\title{
The SmartSantander Project
}

\author{
José M. Hernández-Muñoz ${ }^{1}$ and Luis Muñoz ${ }^{2}$ \\ ${ }^{1}$ Telefonica I+D, Madrid, Spain \\ jmhmatid.es \\ ${ }^{2}$ Universidad de Cantabria, Santander, Spain \\ luis@tlmat.unican.es
}

\begin{abstract}
The SmartSantander project has deployed during the past two years a unique in the world city-scale experimental research facility in support of typical applications and services for a smart city. This facility is sufficiently large, open and flexible to enable horizontal and vertical federation with other experimental facilities, and to stimulate the development of new applications by end-users. Besides, it provides support to the experimental advanced research on IoT technologies, and allows a realistic assessment on new services by means of users' acceptability tests. The facility already counts with more than 10,000 IoT devices (March 2013), and by the end of 2013 it will comprise of more than 12,000. The core of the facility is being installed in the city of Santander (Spain), the capital of the region of Cantabria situated on the north coast of Spain, and its surroundings. Besides Santander, other deployments have been placed in Lübeck (Germany), Guilford (UK) and Belgrade (Serbia). SmartSantander will enable the Future Internet of Things to become a reality.
\end{abstract}

Keywords: SmartCity, IoT, IoS, testbed, Future Internet.

\section{The Service/Experimentation Duality}

The testbed has being designed and implemented to operate in a scalable, heterogeneous and trustable way, thus becoming a flexible large-scale real-world experimental facility. Besides providing support to scientific experimentation, SmartSantander is also granting benefits of the massive IoT infrastructure deployed to the citizenship by providing support to end-user services in the framework of the city. The deployment into a realistic environment will not only secure sustainability through direct value generation for its users, but also drive the facility to evolve and dynamically adapt to the changing conditions of the everyday life in the city.

\section{A Real-Life, Large-Scale Facility}

One of the main objectives of the project is to fuel the use of the facility among the scientific community, end users and service providers in order to reduce the technical and societal barriers that prevent the IoT paradigm to become an everyday reality.

To attract the widest interest and demonstrate the usefulness of the SmartSantander platform, a key aspect has been from the very beginning the inclusion of a wide set of 
applications areas. With this principle in mind, a number of key use cases have been selected based on their potential impact to the citizenship as well as their ability to exhibit the diversity, dynamics and scale that are essential in advanced protocol solutions. The high oversubscription experimented in the two open calls released so far have demonstrated that the ability to evaluate technologies and use cases by means of the platform is highly attractive for all involved stakeholders: industries, communities of users, other entities that are willing to use the experimental facility for deploying and assessing new services and applications, and Internet researchers to validate their cutting-edge technologies (protocols, algorithms, sensor platforms, etc.).

Some details of the experimental facility corresponding to the parking management scenario, where sensors have been deployed in one of the streets parallel to the sea and close to Santander downtown, are show in Fig. 1.
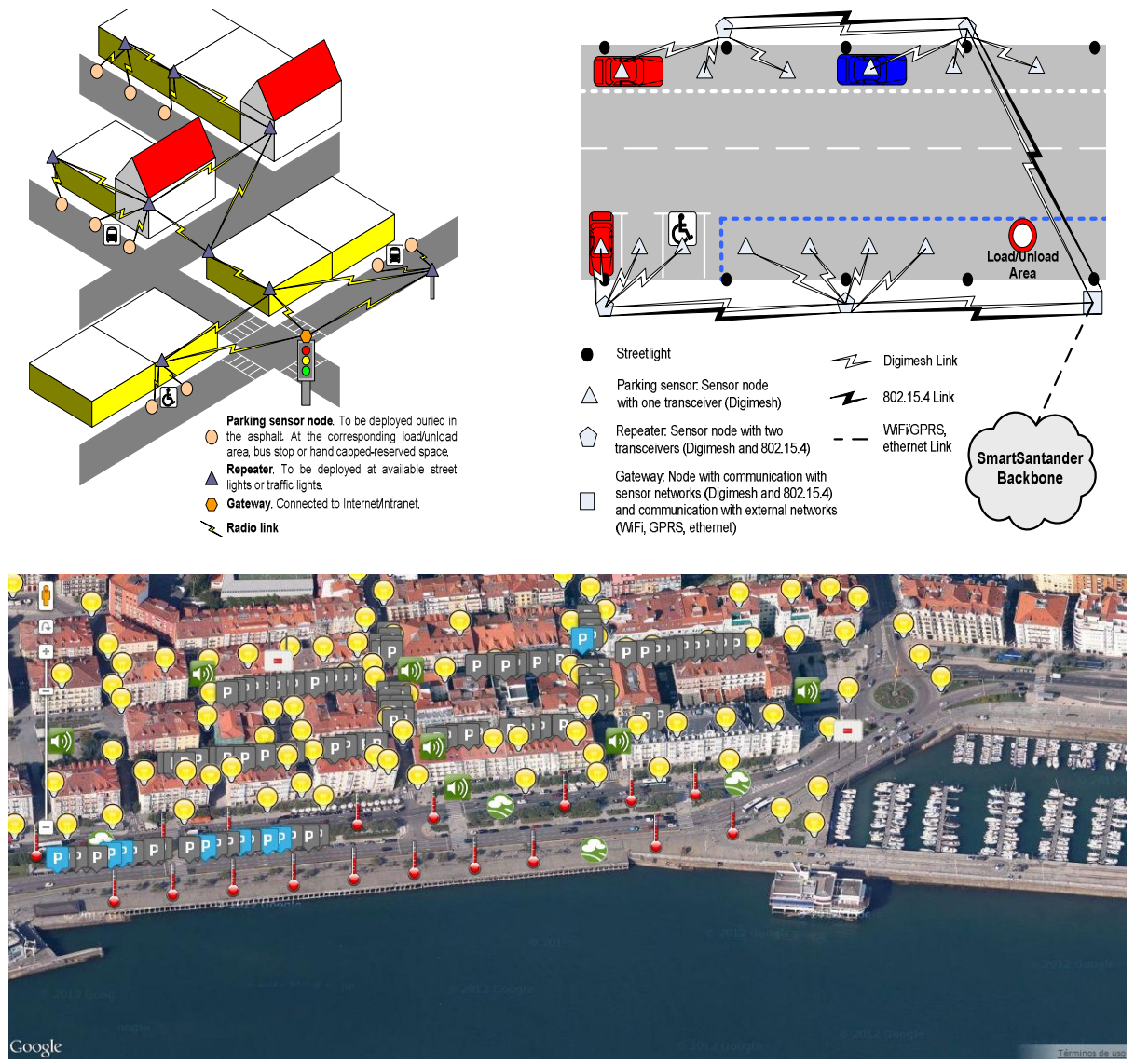

Fig. 1. Overview of a small part of the infrastructure deployed in Santander

Open Access. This article is distributed under the terms of the Creative Commons Attribution Noncommercial License which permits any noncommercial use, distribution, and reproduction in any medium, provided the original author(s) and source are credited. 